\title{
Brincando e aprendendo nos mundos virtuais: o potencial educativo dos games de simulação*
}

Dulce Márcia Cruz

Doutora em Engenharia de Produção - UFSC.

Professora do Departamento de Metodologia de Ensino - MEN,

Centro de Educação - CED, Universidade Federal de Santa Catarina - UFSC.

E-mail: dulce.marcia@gmail.com

Paulo César Abdalla Ilha

Bacharel em Comunicação Social - FURB

E-mail: pauloilha84@yahoo.com.br

Resumo: Este artigo descreve uma pesquisa que investigou como os docentes do Ensino Médio podem traduzir conteúdos e estratégias didáticas de suas disciplinas usando games e quais mudanças eles percebem na criação, administração e regulação das situações educacionais com o uso da inovação. A pesquisa foi realizada entre 2003 e 2004 na Escola Técnica do Vale do Itajaí (ETEVI), ligada à FURB, Universidade Regional de Blumenau, acompanhando o trabalho dos professores de Português, Matemática e Geografia. A partir de uma breve revisão da literatura sobre a função social e educacional do lúdico e as características dos ambientes digitais, o artigo descreve as possibilidades narrativas do game SimCity4, o planejamento dos professores em relação às atividades com o jogo e os resultados da experiência-piloto com os alunos durante um semestre.

Palavras-chave: cibercultura, games de simulação, SimCity4, ambiente virtual de aprendizagem, mídia-educação.
Abstract: The present paper describes the results from a research that investigates how teachers translate the didactic contents and strategies of their disciplines using games and what are the changes they perceive in their creation, management and regulation processes for the learning situations in the classroom using innovation. The research was conducted between 2003/2004 at the Escola Técnica do Vale do Itajaí (ETEVI), at Regional University of Blumenau (FURB), following three high school teachers (Portuguese, Math and Geography). Following a brief review of the literature on playful activities and the social and educational function of playing, this paper analyses the narrative possibilities of the game SimCity4, as well how the teachers chose the selected game, planned of the activities with the game and what were the results of the pilot experiment with the students in one semester.

Keywords: cyberculture; simulation games; SimCity4; learning virtual environment; media education.
Recebido: 07/05/2007

Aprovado: 13/08/2007

* Artigo baseado em relatório final de pesquisa realizada com recursos do $\mathrm{PIBIC/FURB.}$ 
1. HUIZINGA, Johan. Homo Ludens: o jogo como elemento da cultura. São Paulo: Perspectiva, 1993. (Estudos 4).

2. KISHIMOTO, Tizuko Morchida. $\mathrm{O}$ jogo e a educação infantil. São Paulo: Pioneira, 1994, p. 30.

3. PIAGET, Jean. A formação do símbolo na criança: imitação, jogo e sonho. 3. ed. Rio de Janeiro: Zahar Editores, 1978.

4. KISHIMOTO, op. cit.

5. TAPSCOTT, Don. Geração digital: a crescente $e$ irreversível ascensão da geração Net. São Paulo: Makron Books، 1999.

6. GREENFIELD, Patrícia Marks. $O$ desenvolvimento do raciocínio na era da eletrônica: os efeitos da TV, dos computadores e videogames. São Paulo: Summus, 1988. p. 114.

7. HOSTETTER, Obe. Video Games. The Necessity of Incorporating Video Games as part of Constructivist Learning (2002). Game Research 2004. Disponível em: $<$ http://www.game-research.com/art_games_contructivist.asp $>$. Acesso em: 8 jul. 2004.

8. KRÜGER, Fernando Luiz; CRUZ, Dulce Márcia. Os jogos eletrônicos de simulação e a criança. Revista Fronteiras, Estudos Midiáticos, São Leopoldo-RS, v. IV, n. 1, p. $65-80,2002$
A brincadeira e o jogo possuem funções importantes na sociedade. A principal delas é a forma lúdica pela qual se manifestam, proporcionando lazer e diversão. O jogo completa o conhecimento do indivíduo, em um ambiente livre de pressões, adequado para a investigação, exploração e resolução de problemas $^{1}$. Nas brincadeiras de miniaturas ou de faz-de-conta, as crianças imitam os adultos com o intuito de pré-exercitar as funções da vida adulta, passando a compreender a realidade, pois "construindo, transformando e destruindo, a criança expressa o seu imaginário e seus problemas"', diz Kishimoto. Dessa maneira, a construção estimula a imaginação das crianças. Kishimoto também considera importante o planejamento das construções, a previsão de um modelo idealizado antes de partir para a ação. Esse esforço mental (imaginando o que irá se produzir) colabora para o desenvolvimento da inteligência e da criatividade.

Para Piaget, o conhecimento não é uma cópia da realidade 3 . O processo não consiste em olhar para o objeto e fazer uma cópia mental. Conhecer um objeto é agir sobre ele, modificando-o, transformando-o e compreendendo-o. $\mathrm{Na}$ vida cotidiana as pessoas geralmente inventam e reinventam situações a fim de aprender com elas. Kishimoto ${ }^{4}$ afirma que o jogo favorece o aprendizado pelo erro e, por ser livre de pressões e avaliações, cria um clima adequado para a investigação e a busca de soluções. O benefício do jogo está na estimulação dessa exploração, em que é permitido errar.

Por suas características lúdicas e atrativas, os jogos eletrônicos, ou games, têm aparecido como uma possibilidade de encantar a educação para jovens. Tapscott defende o método de ensino mais criativo, que torna o aprendizado divertido estimulando o estudante a obter o conceito do aprendizado através da descoberta ${ }^{5}$. Esse método difere-se do tradicional ensino por memorização, principalmente pela motivação que proporciona ao aluno, unindo diversão ao aprendizado. Segundo Greenfield, ao acrescentar imagens visuais dinâmicas, as informações apresentadas verbalmente se tornam mais fáceis de ser lembradas: "Ao contrário da leitura, do rádio ou da televisão, a tecnologia interativa para computadores pode propiciar à criança o papel ativo tão essencial ao processo de aprendizagem" ${ }^{6}$. Segundo Hostetter ${ }^{7}$, os games podem ser utilizados com muito sucesso na educação porque mudaram as habilidades cognitivas dos aprendizes. Para o autor, videogames são uma excelente ferramenta de aprendizagem porque o computador pode se ajustar às dificuldades de acordo com as preferências ou necessidades do jogador. Esses games também podem ensinar raciocínio dedutivo e estratégias de memorização, auxiliando no desenvolvimento da psicomotricidade, principalmente porque exercita a coordenação entre o olhar e a reação das mãos.

Neste sentido, os games de simulação apresentam um ambiente virtual onde a criança exerce ação e controle sobre os elementos, representando a junção da diversão do jogo com o ambiente operacional da máquina, permitindo ao usuário utilizar o computador como um poderoso veículo para criação de histórias ${ }^{8}$. Além disso, o fascínio dos ambientes digitais, segundo Murray, re- 
side na possibilidade de o jogador usufruir de três prazeres: o de imersão, o de agência e o de transformação. $O$ prazer de imersão é o que nos permite a sensação de estarmos totalmente envolvidos por uma realidade completamente estranha, na qual podemos encenar nossas fantasias, vivendo a experiência de sermos transportados para um lugar primorosamente simulado, cuja vivência é prazerosa em si, independentemente do conteúdo da fantasia. No prazer de agência, quanto mais estivermos imersos no ambiente digital, mais desejamos agir dentro dele, mais ativos queremos ser e ter resultados tangíveis. Agência é para Murray "a capacidade gratificante de realizar ações significativas e ver resultados de nossas decisões e escolhas" ${ }^{\prime}$. O terceiro prazer do ambiente digital vem do poder de transformação extremamente sedutor que o computador permite nos ambientes narrativos, pois neles "não tomamos decisões para a vida inteira ou por toda civilização; quando as coisas dão errado, ou quando simplesmente queremos uma outra versão da mesma experiência, voltamos para o início e começamos de novo" ${ }^{" 10}$.

\section{METODOLOGIA}

O projeto de pesquisa que descrevemos aqui investigou essa capacidade de construção e destruição dos games através de uma experiência com professores e alunos da Escola Técnica do Vale do Itajaí (ETEVI), ligada à Universidade Regional de Blumenau (FURB). O jogo escolhido foi o SimCity4, porque ele possibilita a qualquer usuário, adulto ou criança, simular a construção de cidades de modo lúdico, instigante e desafiador. Pesou também para a escolha o fato de uma das professoras integrantes do projeto saber jogar o anterior, SimCity 3000, e propor que esse fosse o ponto de partida para a escolha do game.

Quando lançado em 1989, o SimCity foi um marco na história dos games. Pela primeira vez, um jogo poderia transportar todo o dia-a-dia de uma cidade para dentro da casa do jogador. Nos anos seguintes, foi aprimorado com versões cada vez mais sofisticadas, culminando em 2003 com o lançamento da versão quatro. De modo resumido, o SimCity 4 caracteriza-se por colocar o usuário na função de prefeito de uma cidade nascente. O jogador tem o objetivo de administrar a cidade e fazê-la prosperar, tomando diversas decisões nos âmbitos financeiro, ético, estético, cultural e administrativo. A questão burocrática, por exemplo, é muito fiel à realidade, pois o jogador pode controlar tudo, desde leis, impostos, verbas para educação, hospitais e transportes. Para gerir o desenvolvimento de sua cidade virtual, o jogador conta com uma série de ferramentas que abrem uma outra de hipertextos e permitem ao software simular a conseqüência das atitudes tomadas pelo jogador. Dentre as diversas ações, o SimCity 4 possibilita demarcar as áreas de residência, comércio e indústrias e criar um mapa tridimensional com montanhas, vegetação, vales, florestas, rios, lagos, mares e animais de várias espécies.
9. MURRAY, Janet $\mathrm{H}$. Hamlet no Holodeck: o futuro da narrativa no ciberespaço. São Paulo: Itaú Cultural/Unesp, 2003 p. 127.

10. lbid., p. 153. 
Em agosto de 2003 apresentamos o projeto para a direção da ETEVI, que se colocou à disposição para auxiliar na execução e incentivar a adesão dos professores. A diretora da escola sugeriu que participassem professores do primeiro ano do ensino médio, cuja faixa etária dos alunos é mais próxima do público-alvo dos games estudados, e por não interferir em turmas com períodos tumultuados pela proximidade do vestibular.

Após muitas reuniões com os docentes para explicar o projeto, em outubro de 2003 os professores de Matemática, Geografia e Língua Portuguesa decidiram colaborar com a nossa pesquisa. A partir desse momento, eles tiveram um contato supervisionado com o game, para obter as informações necessárias e fazer o planejamento de sua utilização em sala de aula. Para isso, realizamos algumas reuniões de aprendizagem do jogo, para a compreensão da dinâmica, da lógica e do vislumbre das possibilidades educacionais do game. Durante essa capacitação, os professores demonstraram facilidade de identificação de estratégias didáticas diretamente relacionadas ao jogo. A partir dessa familiarização e da discussão das estratégias possíveis de serem trabalhadas, eles redigiram um projeto que foi aprovado no colegiado da ETEVI para iniciar-se em 2004'.

Enquanto os professores planejavam suas aulas com o SimCity4, a pesquisa enfrentou uma série de obstáculos para que os alunos começassem a participar: questões técnicas (falta de placas e computadores com capacidade necessária nos laboratórios), burocráticas (demandas de direito autoral quanto ao uso do jogo), organizacionais (inexistência de dotação no orçamento da pesquisa para compra dos games e dos equipamentos) e institucionais (proibição de instalar o software e jogar nos computadores da escola). O projeto só pôde ser levado para a sala de aula no mês de maio de 2004, três meses após o previsto. Também tivemos que desistir de realizar um piloto de teste e passamos direto ao uso do jogo nas aulas. Apesar do atraso, os professores envolvidos se mostraram entusiasmados e não desanimaram durante o período de espera. A direção da escola nos informou que os pais dos alunos também estavam animados com a perspectiva de uma melhoria na qualidade do ensino.

A metodologia utilizada no uso do jogo será descrita a seguir, a partir da fala dos professores envolvidos, para demonstrar o quanto eles e a direção da escola aderiram à pesquisa e criaram estratégias de utilização do game de forma inovadora. A experiência durou cerca de dois meses e foi realizada com uma turma de 1르 Série do Ensino Médio da ETEVI, considerada problemática pelo alto número de repetência entre os alunos.

\section{DESCRIÇÃO E ANÁLISE DOS RESULTADOS}

A professora de Geografia começou o contato dos alunos com o jogo, já

11. ETEVI. Projeto SimCity. Blumenau: ETEVIFURB, 2004. Mimeo. que foi em sua disciplina que as cidades começaram a ser construídas. Ela trabalhou em seis encontros de cerca de 90 minutos cada, e assim descreveu sua metodologia: agrupados em três e quatro alunos, cada equipe teve um 
momento inicial para o aprendizado parcial das ferramentas que o game oferecia. Após esse momento, cada grupo recebeu um relatório com informações a serem construídas conforme o andamento do jogo. Todo encontro para o jogo vinha acompanhado de vários questionamentos dos grupos, podendo-se trabalhar um amplo conhecimento geográfico em qualquer momento, aliado à riqueza enorme de detalhes que o game oferece.

A professora P. G., de Matemática, relatou que dividiu a turma em grupos e trabalhou com eles a administração do orçamento, buscando construir a cidade e ao mesmo tempo manter a saúde financeira da prefeitura. Ela usou elementos de matemática financeira, geralmente impossíveis de serem tratados nessas aulas, mas abordados a partir da simulação das situações dentro do jogo.

Os mesmos grupos foram trabalhados pelo professor A. C. S., de Língua Portuguesa, realizando as seguintes atividades durante a construção da cidade, em dois meses:

a) justificar por escrito a escolha do nome da cidade;

b) narrar por escrito, de forma literária e jornalística, uma situação vivenciada no jogo;

c) caracterização do prefeito como personagem, seus níveis de linguagem produzindo um texto crítico;

d) formulação de perguntas a outra equipe sobre dúvidas com relação ao jogo para discutir o resultado na aula de Geografia;

e) participação num fórum virtual, respondendo a questões sobre a função da imprensa na sociedade, os desafios vividos com a experiência de liderança e poder no SimCity4, como o aluno se sentiu sendo prefeito de uma cidade com problemas e tendo que tomar decisões sob pressão da população;

f) participação oral num debate sobre os prós e contras de uma posição de liderança;

g) confecção de um relatório final sobre as atividades desenvolvidas com o uso do SimCity4 nas disciplinas envolvidas no projeto.

A professora M. H. B. C., de Geografia, comentou a reação dos alunos:

[...] ficou evidente a motivação do aluno por estar fugindo do lugar-comum da sala de aula, assim como também se percebe o despreparo dos corpos discente e docente em envolver-se com uma nova proposta. Aos alunos, a dificuldade reside muito em sistematizar as informações do jogo e ligar o lúdico ao conhecimento científico ("jogo não é aula”). A nós, a compartimentalização disciplinar é um método ainda a ser quebrado, seja nos horários ou nos planos de ensino de cada professor ("estou perdendo aula", "meu conteúdo fica atrasado").

Em sua avaliação do uso do jogo, o professor de Língua Portuguesa considerou que

[...] apesar das diversas dificuldades relativas ao interesse de certos alunos e ao comprometimento deles para com o próprio aprendizado, o projeto foi extremamente válido para os estudos de língua portuguesa, uma vez que atende perfeitamente aos objetivos da disciplina no ensino médio, ou seja, fornecer ao 
aluno condições para que se posicione crítica e competentemente ante as mais diversas situações do cotidiano. A língua foi utilizada como instrumento social para a busca de soluções para problemas normais da sociedade e para a promoção da interação e da construção de conhecimentos. Dessa forma, considera-se importante, válido e de grande valia o uso do jogo SimCity, sendo este um facilitador e um mediador do processo de ensino e aprendizagem, que age de forma eficiente, despertando o interesse dos alunos.

A avaliação da aprendizagem no caso da Geografia

[...] foi pensada inicialmente como uma conseqüência do andamento do jogo, promovendo-se um quase desligamento dos encontros com a nota. Infelizmente não foi possível. O aluno ainda é movido pela mola mestra, razão única de sua estada em sala. Desvinculando-se a nota do jogo, o aluno não encontrava necessidade de sistematizar as informações do relatório. Aí reside, bem como na sistematização, o grande foco do objetivo do projeto. Que o jogo venha acompanhado da necessidade de conhecimento e não de nota. Assim, a avaliação foi feita individualmente, apresentando-se situações do saber geográfico e cabendo ao aluno a ligação das situações apresentadas com sua experiência no jogo. Mesmo que nem todos tenham conseguido realizar com sucesso o trabalho proposto, ainda assim o nível de apreensão dos conceitos e fundamentos da Geografia pelos alunos durante o jogo foi mais profundo, pois veio acompanhado de todo um caráter visual e lúdico, que o jogo possibilita de forma ímpar.

Ao final dos dois meses de trabalho, o grupo se reuniu num grande seminário com os alunos, sob orientação e mediação dos professores-coordenadores e da supervisão pedagógica, para apresentar resultados, relatar experiências e avaliar o projeto no todo. Em seu depoimento, a professora de Matemática afirmou que achou muito rico o uso do jogo em sua matéria, apesar de ter tido muitas dificuldades e angústias, principalmente em relação ao comprometimento de alguns alunos que não ocorreu como ela esperava.

No depoimento dos alunos durante a reunião, percebemos que a maioria tinha gostado da experiência e alguns haviam se envolvido muito com a construção da cidade e da resolução dos problemas de seus moradores. Os depoimentos mostraram que as questões do poder, de solucionar as demandas da população e, ao mesmo tempo, de não ter problemas de caixa trouxeram um questionamento sobre como ocorre a administração de uma cidade real e suas dificuldades. Também apareceram diversos questionamentos sobre as dificuldades de se desenvolver uma cidade sem poluir, mantendo empregos sem destruir o meio ambiente. Um comentário geral entre os alunos foi que a participação de outros professores (Filosofia, História ou mesmo Física) teria sido enriquecedora pelos diferentes aspectos que foram levantados durante as aulas.

$\mathrm{Na}$ avaliação da equipe de professores-coordenadores, supervisão pedagógica e a direção da escola, o projeto foi aprovado como uma experiência inovadora e potencialmente enriquecedora da aprendizagem. Assim, foram incorporados novos professores ao grupo pesquisado e iniciada ainda no segundo semestre letivo de 2004 uma segunda experiência, dessa vez com uma outra turma de $1^{\text {a }}$ Série do Ensino Médio. A partir de 2005, o projeto de uso do jogo foi retomado 
Brincando e aprendendo nos mundos virtuais - Dulce M. Cruz e Paulo C. A. Ilha

durante as aulas, independentemente da participação destes pesquisadores, por iniciativa dos professores da própria escola.

\section{CONCLUSÕES}

O entusiasmo dos professores e a perspectiva declarada por eles de que, após essa primeira etapa, a escola iria expandir a experiência para outras turmas, demonstra que havia uma expectativa grande também dos alunos sobre a melhora na aprendizagem com o uso do game. Percebe-se, dessa maneira, que há espaço para essas experiências interdisciplinares, que os professores estão abertos a tais alternativas didáticas e que, mesmo com dificuldades burocráticas, a persistência se mantém. Outra conclusão é a de que a FURB, como talvez outras instituições brasileiras de ensino superior, não está preparada para responder a demandas de uso de novas tecnologias na sala de aula, especialmente com relação a questões e necessidades que ainda não tenham sido levantadas anteriormente.

A experiência revelou que, apesar da boa vontade dos professores, ainda há muito o que aprender com relação ao encaixe de atividades lúdicas dessa natureza na sala de aula. Por parte dos alunos, o problema é que eles não vêem com muita seriedade a entrada de um tipo de entretenimento que normalmente não faz parte da escola, e, por essa razão, precisa ser mensurado a partir dos métodos tradicionais, com avaliação e notas, para adquirir o status de conhecimento escolar. No caso da experiência narrada, os limites institucionais pesaram na questão do tempo dedicado ao jogo, que não pôde ser maior. Esse foi um fator restritivo, já que, provavelmente, os alunos teriam aproveitado melhor as possibilidades do jogo se tivessem mais aulas e grupos menores por máquina para poderem jogar e efetivamente sentir o prazer descrito por Murray - o de estar imersos e ser agentes e transformadores.

No entanto, a continuidade do projeto e o interesse despertado na direção da escola, nos professores, alunos e pais mostrou que o lúdico e, especialmente, os jogos eletrônicos podem ser mais uma forma agradável de se trabalhar o conhecimento e algumas habilidades na sala de aula. A pesquisa sugere que as instituições deveriam se preparar para abrir espaço para que a criatividade de professores inovadores possa incorporar outros processos de aprendizagem adaptados dos ambientes extra-escolares. Neste sentido, mais pesquisas que busquem experimentar essas novas possibilidades serão bem-vindas.

\section{REFERÊNCIAS BIBLIOGRÁFICAS}

ETEVI. Projeto SimCit. Blumenau: ETEVI-FURB, 2004. Mimeo.

GREENFIELD, Patrícia Marks. O desenvolvimento do raciocínio na era da eletrônica: os efeitos da TV, dos computadores e videogames. São Paulo: Summus, 1988. 
comunicação \& educação • Ano XIII • Número 2 - maio/ago 2008

HUIZINGA, Johan. Homo Ludens: o jogo como elemento da cultura. São Paulo: Perspectiva, 1993. (Estudos 4).

KISHIMOTO, Tizuko Morchida. O jogo e a educação infantil. São Paulo: Pioneira, 1994.

KRÜGER, Fernando Luiz; CRUZ, Dulce Márcia. Os jogos eletrônicos de simulação e a criança. Revista Fronteiras, Estudos Midiáticos, São Leopoldo-RS, v. IV, n. 1, 2002.

MURRAY, Janet H. Hamlet no Holodeck: o futuro da narrativa no ciberespaço. São Paulo: Itaú Cultural/Unesp, 2003.

PIAGET, Jean. A formação do símbolo na criança: imitação, jogo e sonho. 3. ed. Rio de Janeiro: Zahar Editores, 1978.

TAPSCOTT, Don. Geração digital: a crescente e irreversível ascensão da geração Net. São Paulo: Makron Books, 1999.

\section{Endereço eletrônico}

$<$ http://www.game-research.com/art_games_contructivist.asp $>$ 